\title{
Evaluating the Effectiveness of Classroom Discussion Approaches Used in the Remote Delivery of Systems Engineering Education
}

\begin{abstract}
This paper addresses the effectiveness of classroom discussion approaches used in the remote online delivery of graduate level systems engineering education at the Stevens Institute of Technology during the Fall 2009 semester. Twenty-two unique systems engineering graduate level core and elective courses, covering systems engineering curriculum content in three of the five levels of the evolved INCOSE graduate systems engineering reference curriculum, were offered in thirty-two course sections over the 15week Stevens Webcampus semester. We measured effectiveness of the classroom discussion approaches used by analyzing the student's self-reported satisfaction with the learning experience, and categorizing the results by the frequency (how often) and type (asynchronous online text-based versus real-time live audio-based) of classroom discussion employed in each course. Findings indicated that Fall 2009 students were generally more satisfied with instructor quality versus course quality across the board. A best practice was evident in the use of asynchronous remote online discussions only (no real-time discussions) - whether faculty participated in those discussions or not; and results from the courses that leveraged real-time webconferences or the combination of real-time webconferences and asynchronous online discussions, were mixed.
\end{abstract}

\section{Introduction}

In the sixth annual Sloan Consortium report on online higher education in the United States, Allen (2008) states: "Online enrollments have continued to grow at rates far in excess of the total higher education student population, with the most recent data demonstrating no signs of slowing." (p. 1) As a result of these trends, online andragogy (theory of adult learning) has earned a prominent place within engineering education research. The effectiveness of online andragogy in teaching engineering and science, however, is poorly understood. Currently, the perceived effectiveness of online teaching and learning lies on a continuum. At one extreme is the perception that without a physical setting - that allows one to see and identify with class members and interpret tone of voice and body language along with the spoken word - an acceptable level of learning cannot be achieved. This end of the continuum typically includes those who have been highly successful in educating and learning in the physical world. At the other extreme is the belief that the online venue is the solution for nearly every challenge facing today's educational system. Clearly the actuality lies somewhere in-between. In this paper we will leverage data provided from the student perspective on perceived quality of remote online systems engineering education to investigate where their learning experience belongs along this continuum.

As demand for online courses has increased, informal experiments have been taking place online, and a great deal of data has been collected and stored. However, only a small subsection of this data has been analyzed or reviewed for applicability to general educational theory and specifically to systems engineering education research. One area 
that remote education research consistently emphasizes is the importance of interactions among students and between the instructor and the students. ${ }^{4,5,16}$ In reference to asynchronous remote online course design research, Swan (2000) found: "...three (and only three) course design factors that contribute significantly to the success of online courses. These are a transparent interface, an instructor who interacts frequently and constructively with students, and a valued and dynamic discussion." (p. 517)

To this end, we are interested in the challenges and achievements of remotely delivered systems engineering education in the context of discussion andragogy; that is, in the context of the approach used to enable student and faculty discussion of course content where the students are remote from the faculty and each other. Therefore, we focus in this paper on the area of classroom discussions. We analyze the method of classroom discussion used in the delivery of thirty-two instantiations of twenty-two unique systems engineering graduate level core and elective courses via the Stevens Webcampus program during the Fall 2009 semester. We compare the frequency and type of discussions held online and the level of faculty participation in these text-based discussions along with the frequency of real-time web conferencing discussions, to overall student satisfaction with the learning experience as reported by the student through online course evaluations. Based on these empirical results, we include suggested best practices as well as areas for future research in remote classroom discussions for systems engineering and related education.

\section{Background}

The school's online educational approach is founded on an 'anywhere, anytime' instructional framework. ${ }^{10}$ A typical online course at the Stevens Institute of Technology consists of the delivery of course content by an experienced instructor to remote students over the Internet. Each instructor sets up their course content in the university's Web Course Tools (WebCT) Learning Management System (LMS) as part of the Webcampus program. Built courses include a student code of conduct, a faculty introduction or profile, a course syllabus and/or an overview for getting started, course material including lecture notes and additional resources, chat rooms and discussion groups, webconferencing rooms, and other useful information and links. Each course contains the necessary components to address Moore's (1989) three types of interaction: learnercontent, learner-instructor, and learner-learner; ${ }^{8}$ as well as Hillman's (1994) fourth type of interaction: learner-interface. ${ }^{6}$ The school's philosophy for the development of remote online courses supports Parker's (1999) conclusion that interactions in the online environment "...can be defined as active learning". 9 and learning is the ultimate goal.

The Systems Engineering and Engineering Management department of the Stevens Institute of Technology began delivering remote asynchronous graduate level systems engineering courses in the Spring of 2003 with the online delivery of the program's core graduate level systems engineering course: Fundamentals of Systems Engineering. While the course began with a real-time live web-conference that all students were required to attend to review the expectations for the course, delivery was primarily through a textbased format. That is, throughout the rest of the course, the instructor and the students 
interacted asynchronously through text-based exchange within the Web Course Tools (WebCT) Learning Management System (LMS). Delivery consisted of posting weekly course content in the form of presentations, participating in required weekly online discussions, and working together with a team to produce a final team project. The initial course was offered to sponsored corporate students in a condensed six-week format and the initial courses were used primarily for systems engineering training. In 2005, audio lectures were added to the weekly course content; yet follow-on comparative research indicated that: "... where there is evidence that the inclusion of audio lectures in the online format increases student satisfaction, it may not necessarily improve student learning." $" 15$ The findings of the research indicated that additional assessment and evaluation needs to be done to understand which components of online education are best suited for accelerated learning.

Over the past eight years, the number and type of courses offered online through the School of Systems and Enterprises have grown. To put them in context, the twenty-two courses offered through the Stevens Webcampus Fall 2009 semester map to the 'further' evolved INCOSE graduate systems engineering reference curriculum framework ${ }^{13}$, illustrated in Figure $1^{13}$, as shown in Table $1 .^{13}$

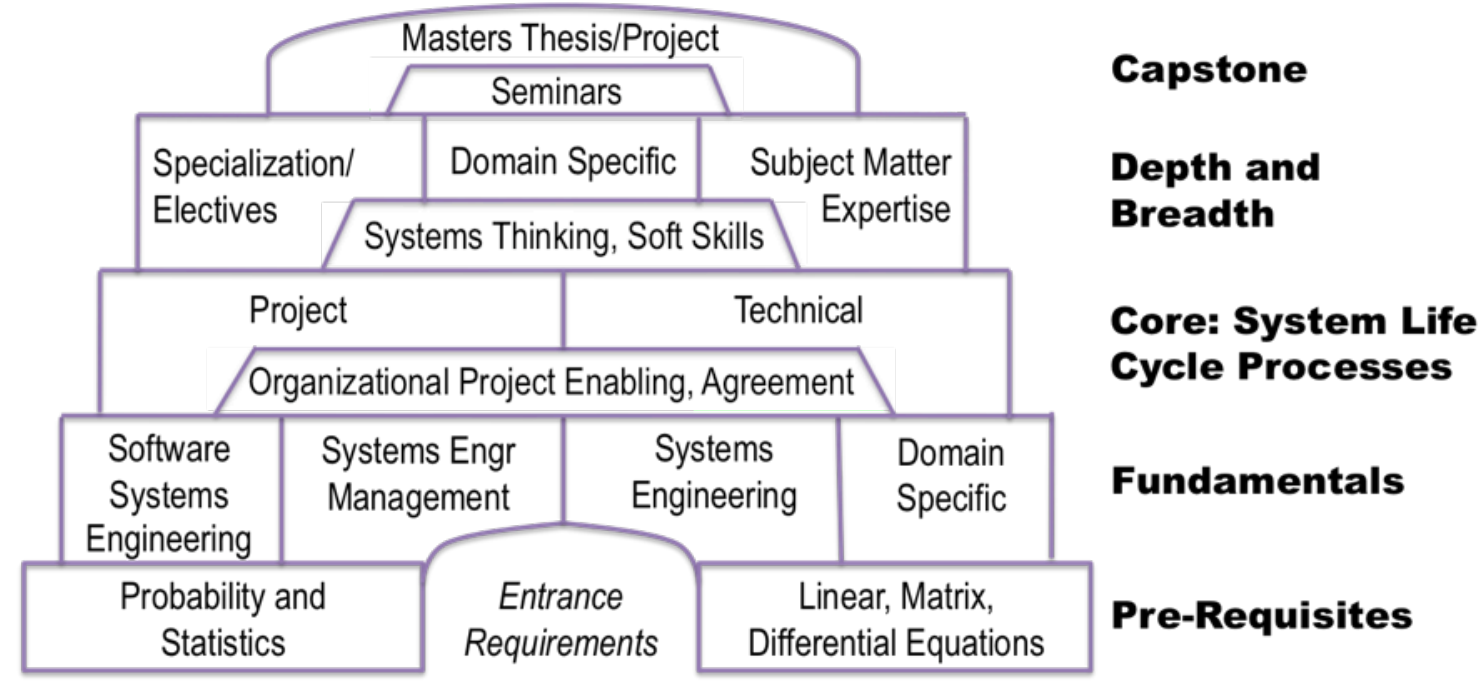

Figure 1. Building a Curriculum from the Evolved INCOSE Graduate Systems Engineering Reference Framework ${ }^{13}$

As the curriculum has expanded, certain standardization approaches have been of benefit. For example, when the program was just getting started, instructors had the liberty to create a unique course interface based on their style and individual preferences. However, this placed a burden on the student as the student moved from course to course. This inconsistency in interface appeared to impact the student's satisfaction with the learning experience. ${ }^{14}$ However, based on the outcome of research on the effectiveness of online course components and the impact of a non-transparent interface ${ }^{14}$, all of the Stevens' School of Systems and Enterprises courses offered through Webcampus were redesigned in the Fall of 2007 and the Spring of 2008 to provide a consistent course interface to the student; and as a result student satisfaction improved across the program. 


\section{Table 1. Context of 22 Webcampus Courses Within Evolved INCOSE Graduate Systems Engineering Reference Framework ${ }^{13}$}

\begin{tabular}{|c|c|}
\hline $\begin{array}{l}\text { Course Groupingsfrom } 2006 \text { Study Merged with } \\
\text { ISO/IEC 15288:2008 System Life Cycle Processes* }\end{array}$ & $\begin{array}{l}\text { School of Systems and Enterprises, Stevens } \\
\text { Webcampus Courses Offered Fall } 2009\end{array}$ \\
\hline \multicolumn{2}{|c|}{ Pre-Requisite Courses } \\
\hline Probability and Statistics & Probability Theory for Financial Engineering \\
\hline Linear, Matrix, Differential Equations & Stochastic Calculus for Financial Engineers \\
\hline \multicolumn{2}{|c|}{ Fundamentals } \\
\hline Fundamentals of Systems Engineering & Fundamentals of Systems Engineering \\
\hline Fundamentals of Software Systems Engineering & Fundamentals of Software Engineering \\
\hline Introduction to Systems Engineering Management & - \\
\hline Introduction to Domain Specific & Engineering of Large Software Systems \\
\hline \multicolumn{2}{|c|}{ System Life Cycle Technical Processes } \\
\hline $\begin{array}{c}\text { Mission Needs, System Concept, Stakeholder } \\
\text { Requirements Definition, Requirements Analysis, System } \\
\text { Requirements }\end{array}$ & Designing Space Missions and Systems \\
\hline $\begin{array}{l}\text { Systems Architecture, Systems Design and Development, } \\
\text { Modeling, Simulation and Optimization, Implementation }\end{array}$ & $\begin{array}{c}\text { System Architecture and Design } \\
\text { Modeling and Simulation } \\
\text { Software Architecture and Component-based Design }\end{array}$ \\
\hline $\begin{array}{c}\text { Systems Integration and Test, Verification, Transition, } \\
\text { Validation, Field Testing }\end{array}$ & $\begin{array}{c}\text { Systems Integration } \\
\text { Software Testing, Quality Assurance and Maintenance }\end{array}$ \\
\hline $\begin{array}{c}\text { Manufacturing, Production, Operations, Maintenance, } \\
\text { Retirement, Disposal, Systems Suitability }\end{array}$ & Systems Supportability and Logistics \\
\hline \multicolumn{2}{|c|}{ System Life Cycle Project Processes } \\
\hline $\begin{array}{c}\text { Decisions, Risks and Uncertainty, Decision and Risk } \\
\text { Management }\end{array}$ & Decision and Risk Analysis \\
\hline Configuration Management, Information Management & - \\
\hline $\begin{array}{c}\text { Project Management, Finance, Economics, Cost } \\
\text { Estimating and Accounting, Planning, Assessment and } \\
\text { Control, Measurement }\end{array}$ & $\begin{array}{c}\text { Engineering Economics and Cost Analysis } \\
\text { Project Management of Complex Systems } \\
\text { Engineering Cost Management } \\
\text { Software Cost Estimation and Metrics } \\
\end{array}$ \\
\hline \multicolumn{2}{|c|}{ Other System Life Cycle Processes } \\
\hline $\begin{array}{c}\text { Organizational Project-Enabling Processes, Enterprise } \\
\text { Systems }\end{array}$ & Designing and Managing the Development Enterprise \\
\hline Agreement Processes, Acquisition and Supply & - \\
\hline \multicolumn{2}{|c|}{ Depth and Breadth } \\
\hline Systems Thinking & - \\
\hline Engineering Ethics/Legal Considerations & - \\
\hline Negotiation and Influence/Communication** & - \\
\hline Organizational Leadership/Governance & - \\
\hline Creativity and Problem Solving & - \\
\hline Other Soft Skills/Specialization/Electives & - \\
\hline Subject Matter Expertise/Domain Specific & $\begin{array}{c}\text { Pricing and Hedging } \\
\text { Computational Finance } \\
\text { Portfolio Theory and Applications } \\
\text { Advanced Derivatives } \\
\end{array}$ \\
\hline \multicolumn{2}{|c|}{ Capstone } \\
\hline Master's Thesis/Project & - \\
\hline Seminars & - \\
\hline
\end{tabular}

*Adapted from/See Tables VI and VII in Squires (2010) ${ }^{13}$

**New Category Motivated by findings in Armstrong (2009) ${ }^{2}$ 
This trend in leveraging an analysis of student satisfaction to make improvements in online learning is noted by Sener (2003) as "... a vital element in determining the overall quality, success and evolution of online learning environments" (p. 246) ${ }^{12}$ To this end, Sener believes that:

"...the resulting greater attention paid to evaluating online education by using such measures as student satisfaction has not only elevated the practice of online learning but is starting to elevate the practice of traditional education as well. Also, as online education continues to evolve in complexity, the need to evaluate students' satisfaction with their overall learning experiences and with key elements of those experiences grows accordingly." (p. 246)

As a next step in understanding the effectiveness of remote delivery of systems engineering education, we will analyze the impact of different classroom discussion approaches used to discuss systems engineering related course content on self-reported student satisfaction. This will be addressed throughout the remainder of the paper.

\section{Method Used}

What do student satisfaction and online discussions have to do with learning? Kirkpatrick (1998) offers four levels for assessment to achieve quality training. He defines these four levels as: Reaction, Learning, Behavior, and Results (p. 19). ${ }^{7}$ In the context of education, these four levels translate to student satisfaction, student learning, evidence of learning transfer through a change in behavior on the job, and observable results that occur on the job such as improved quality and increased production (p. 23). ${ }^{7}$ Kirkpatrick explains: "Evaluating reaction is the same thing as measuring customer satisfaction. If training is going to be effective, it is important that trainees react favorably to it. Otherwise, they

will not be motivated to learn." (p. 25) 7 Therefore, a first step in assessing the effectiveness of remote online delivery of systems engineering education might lie in an understanding of student satisfaction with the learning experience.

Furthermore, Bender (2003) has devoted an entire book, Discussion Based Online Teaching to Enhance Student Learning: Theory, Practice and Assessment, to the topic of classroom discussion in the online format. ${ }^{3}$ Bender warns us that "... without careful deliberation and intentional focus on the needs to understand pedagogy, as it unfurls online, we run the risk of producing a cohort of students who pass through the educational process, missing out on true opportunities for inspirational and meaningful learning." (p. xv $)^{3}$ The problem that Bender addresses in her warning is driven by the methods being used to meet the growing demand for remote asynchronous online education. Some of the historical approaches used to meet the demand for online education have given online education a bad reputation and put the quality of online education in question. Bender (2003) reminds us: "Online pedagogy is in its infancy." (p. $\mathrm{xv})^{3}$ Because of its short history, there is a dearth of research and knowledge on effective pedagogy in the online environment. 
For these reasons we chose to focus on self-reported student satisfaction to analyze the impact of using various modes of classroom discussion in the remote online classroom. To evaluate the effectiveness of remote delivery of systems engineering education in this context, data was collected from each course delivered online during the Fall 2009 semester in two areas: type and frequency of classroom discussions and self-reported student satisfaction.

\section{Type and Frequency of Classroom Discussions}

First, based on a review of the approaches used for delivering graduate level Webcampus systems engineering core and elective courses in the Fall 2009 semester, the type of classroom discussions were grouped into two major categories: asynchronous online textbased and real-time live audio-based. For the asynchronous online text-based discussions, sometimes referred to as computer-mediated conferences, only those classroom discussions focused on discussing course content were considered in the analysis. That is, online discussions set up in the course for delivering course announcements, exchanging biographical information, addressing questions about the assignments, and other activities that were administrative in nature, were not considered in the analysis. The categories are further defined as shown in Table 2.

Table 2: Categories Defined

\begin{tabular}{|c|l|}
\hline Category & Definition \\
\hline \multirow{4}{*}{$\begin{array}{c}\text { Faculty } \\
\text { Participation }\end{array}$} & $\begin{array}{l}\text { No: instructor added either none or a few active } \\
\text { postings into the active course content } \\
\text { discussions during the entire course, outside of } \\
\text { initiating the discussion, if applicable. }\end{array}$ \\
\cline { 2 - 3 } & $\begin{array}{l}\text { Yes: instructor participated in the course } \\
\text { content discussion at the same level as an } \\
\text { average student or higher }\end{array}$ \\
\hline \multirow{5}{*}{$\begin{array}{c}\text { Frequency } \\
\text { of Discussion }\end{array}$} & $\begin{array}{l}\text { None: no classroom discussions were held to } \\
\text { discuss course content }\end{array}$ \\
\cline { 2 - 2 } & $\begin{array}{l}\text { Periodically: classroom discussions were held } \\
\text { every two to three weeks }\end{array}$ \\
\cline { 2 - 2 } & $\begin{array}{l}\text { Weekly: classroom discussions were held } \\
\text { nearly every week during the course }\end{array}$ \\
\hline
\end{tabular}

\section{Self-Reported Student Satisfaction}

Second, the results from student surveys that contained self-reported course evaluations were collected for every course, and course quality and instructor effectiveness ratings were aggregated into a single value that could be used as a basis of comparison between courses. For these two sections of the survey, students use a Likert based scale to respond with: Strongly Disagree, Disagree, Neutral, Agree, Strongly Agree. 
In summarizing the survey results for each course, an aggregate value for each of the Perceived Course Quality and Percieved Instructor Effectiveness questions is calculated by adapting Frederick F. Reichheld's net promoter methodology ${ }^{11}$ to calculate a Net Supporter \% by taking the percentage of promoters (Strongly Agree) and subtracting the percentage of detractors (Neutral, Disagree and Strongly Disagree) for each of the sixteen statements. According to Reichheld in his article, The One Number You Need To Grow: "The companies with the most enthusiastic customer referrals, including eBay, Amazon, and USAA, receive net-promoter scores of $75 \%$ to more than $80 \%$. For companies aiming to garner world-class loyalty - and the growth that comes with it - this should be the target." (p. 7)

However, this value lies on a scale from $-100 \%$ to $100 \%$. To avoid misinterpretation, the result is normalized to a scale from 0 to $100 \%$ by adding $100 \%$ and then dividing by 2 . For example, a Net Supporters \% value of $80 \%$ would be normalized to $90 \%$. A Net Supporters $\%$ value of $0 \%$ would be normalized to $50 \%$, etc...

The questions asked on the student course evaluation survey, and the choices of answers, are listed for each area in the following sections.

\section{Perceived Course Quality}

Please note: questions 3 and 4 (see below) allow for the N/A (Not Applicable) response since some courses do not have an associated textbook and some courses do not require the student to take quizzes or exams.

1. The course had continuity, not skipping unrelatedly from place to place and was easy to navigate and locate information.

2. My work is graded promptly.

3. The textbook was useful.

4. Exam and quiz questions were a good test of my understanding of the subject.

5. The material was adequately covered in the allotted time.

6. Overall the quality of the course was excellent.

\section{Perceived Instructor Effectiveness}

1. Clearly explains the objectives and the grading system at the start of the course.

2. Is prepared for class.

3. Presents material in an organized manner.

4. Has command of the subject.

5. Successfully communicates the subject matter.

6. Is available to students on matters related to the course.

7. Is fair and consistent.

\section{Overall the instructor was an effective teacher.}




\section{Report of Findings}

The student course evaluation survey response rates exceeded $90 \%$ with 445 of 485 surveys returned at the completion of the Fall 2009 semester. This data represented survey responses for twenty-two unique systems engineering and related courses offered thirty-two times through remote online delivery over a traditional 15-week Stevens Webcampus semester format. This 15 -week format included one week of online orientation, 13 weeks of class, and a finals week. As a baseline, the student satisfaction is summarized for all thirty-two Fall 2009 course deliveries as shown in Table 3. This data represents the baseline data referred to in the remainder of the analysis. Please note that the method of calculations used for each table is summarized in the previous section on 'Method Used'. As a guideline in interpreting the values, according to Reichhold (2003), values in the normalized range above $87.5 \%$ would equate to world class loyalty ${ }^{11}$, whereas any value above $50 \%$ equates to more 'Strongly Agree' responses than the accumulated sum of 'Neutral', 'Disagree' or 'Strongly Disagree' responses.

Table 3. Baseline: True Overall Average of Student-Reported Satisfaction with Course and Instructor Attributes, Normalized on a 0 to $100 \%$ Scale

\begin{tabular}{|l|c|}
\hline \multicolumn{2}{|c|}{ Course } \\
\hline Continuity \& Navigation & $72 \%$ \\
\hline Work Graded Promptly & $65 \%$ \\
\hline Textbook & $56 \%$ \\
\hline Test \& Quizzes & $67 \%$ \\
\hline Adequate Coverage/Time & $67 \%$ \\
\hline Overall Course Quality & $66 \%$ \\
\hline \multicolumn{2}{|c|}{ Instructor } \\
\hline Clear Objectives/Grading & $77 \%$ \\
\hline Prepared for class & $75 \%$ \\
\hline Presents Organized Manner & $70 \%$ \\
\hline Command of Subject & $82 \%$ \\
\hline Successfully Communicates & $71 \%$ \\
\hline Available & $73 \%$ \\
\hline Fair and Consistent & $76 \%$ \\
\hline Overall Effective Teacher & $73 \%$ \\
\hline
\end{tabular}

As shown in Table 3, the area that students were most satisfied with the remote learning experience was in the area of Instructor Quality, rating the highest attribute as:

"Instructor: Has command of the subject." In fact, Instructor Quality was rated higher in every area, overall, as compared to Course Quality, with the exception of one area: "The course had continuity, not skipping unrelatedly from place to place and was easy to navigate and locate information." The area that students were least satisfied was the area of Course Quality that asked about whether: "The textbook was useful." Concerns with the quality of, or more accurately a lack of, a textbook in systems engineering core 
courses are not uncommon. Other areas of Course Quality appear to be viewed about the same, overall, from the student's perspective.

In the next step of the analysis, courses delivered in the Fall 2009 semester were grouped according to the classroom categories previously defined. The grouping resulted in eight distinct categories that are summarized in Table 4.

Table 4. Categorization of Courses by Classroom Discussion Type and Frequency

\begin{tabular}{|c|c|c|c|c|c|}
\hline \multirow{2}{*}{$\begin{array}{c}\# \\
\text { Unique } \\
\text { Courses }\end{array}$} & \multirow{2}{*}{$\begin{array}{c}\# \\
\text { Delivered } \\
\text { Courses } \\
\end{array}$} & \multirow{2}{*}{$\begin{array}{c}\% \text { Online } \\
\text { Student } \\
\text { Enrollments } \\
\end{array}$} & \multicolumn{2}{|c|}{ Frequency of } & \multirow{2}{*}{$\begin{array}{c}\text { Does } \\
\text { Faculty } \\
\text { Participate? }\end{array}$} \\
\hline & & & $\begin{array}{l}\text { Real-Time } \\
\text { Web Mtgs }\end{array}$ & $\begin{array}{c}\text { Online CC } \\
\text { Discussions }\end{array}$ & \\
\hline 2 & 2 & $4 \%$ & None & None & \\
\hline 1 & 1 & $2 \%$ & Periodically & None & \\
\hline 6 & 6 & $14 \%$ & Weekly & None & \\
\hline 1 & 2 & $7 \%$ & Periodically & Periodically & No \\
\hline 6 & 10 & $35 \%$ & None & Weekly & No \\
\hline 3 & 6 & $16 \%$ & None & Weekly & Yes \\
\hline 1 & 2 & $9 \%$ & Periodically & Weekly & Yes \\
\hline 2 & 3 & $13 \%$ & Weekly & Weekly & Yes \\
\hline
\end{tabular}

The following should be noted:

- Student enrollments were nearly evenly split between courses that held real-time web meetings either periodically or weekly (45\%) and those that did not (55\%).

- Eighty percent of student enrollments were in courses that held online discussions either weekly or periodically.

- The most popular online delivery format appears to be courses that include weekly online discussions where the instructor does not hold a weekly real-time web conference; however, a subset of these courses do have recorded audio lectures (not shown in table).

- Of the delivered courses, 7 of the 32 , accounting for $29 \%$ or nearly a third of the student enrollments, instructors used both methods of classroom discussion either periodically or weekly.

The final step of the analysis is to take the student satisfaction data collected from each course and organize the results based on the categories that resulted from the various classifications of each course delivery. The results, based on these groupings, are then compared to the overall baseline results to determine the effectiveness of each classroom discussion approach on self-reported student satisfaction of the learning experience.

Given the three areas of quality comparison, it makes the most sense to perform this step for the two areas of 'Perceived Quality' and 'Comparison Factors'; whereas reasons for enrollment were most likely set before the student had the online learning experience.

After taking the final step, the results for Perceived Quality, with Net Supporters \% (see 'Methods Used') normalized on a 0 to $100 \%$ scale are shown in Table 5. 
Table 5. Perceived Course Quality and Instructor Effectiveness

\begin{tabular}{|l|c|c|c|c|c|c|c|c|}
\hline Real-Time Web Conferences & Weekly & Periodic & None & Periodic & None & None & Periodic & Weekly \\
\hline Online Discussions & None & None & None & Periodic & Weekly & Weekly & Weekly & Weekly \\
\hline Faculty Participation & - & - & - & No & No & Yes & Yes & Yes \\
\hline \multicolumn{7}{|c|}{ Course } \\
\hline Continuity \& Navigation & $69 \%$ & $83 \%$ & $72 \%$ & $50 \%$ & $76 \%$ & $79 \%$ & $64 \%$ & $66 \%$ \\
\hline Work Graded Promptly & $64 \%$ & $72 \%$ & $58 \%$ & $35 \%$ & $70 \%$ & $71 \%$ & $74 \%$ & $63 \%$ \\
\hline Textbook & $76 \%$ & $78 \%$ & $39 \%$ & $50 \%$ & $55 \%$ & $54 \%$ & $52 \%$ & $44 \%$ \\
\hline Test \& Quizzes & $71 \%$ & $50 \%$ & $56 \%$ & $41 \%$ & $72 \%$ & $62 \%$ & $69 \%$ & $70 \%$ \\
\hline Adequate Coverage/Time & $65 \%$ & $67 \%$ & $56 \%$ & $46 \%$ & $75 \%$ & $69 \%$ & $52 \%$ & $63 \%$ \\
\hline Overall Course Quality & $62 \%$ & $\mathbf{6 7 \%}$ & $47 \%$ & $40 \%$ & $\mathbf{7 2 \%}$ & $\mathbf{7 3 \%}$ & $\mathbf{6 9 \%}$ & $66 \%$ \\
\hline \multicolumn{7}{|c|}{ Instructor } \\
\hline Clear Objectives/Grading & $78 \%$ & $72 \%$ & $72 \%$ & $49 \%$ & $80 \%$ & $84 \%$ & $81 \%$ & $72 \%$ \\
\hline Prepared for class & $73 \%$ & $89 \%$ & $75 \%$ & $43 \%$ & $78 \%$ & $83 \%$ & $71 \%$ & $80 \%$ \\
\hline Presents Organized Manner & $64 \%$ & $72 \%$ & $69 \%$ & $39 \%$ & $77 \%$ & $77 \%$ & $62 \%$ & $70 \%$ \\
\hline Command of Subject & $84 \%$ & $89 \%$ & $69 \%$ & $61 \%$ & $84 \%$ & $86 \%$ & $71 \%$ & $87 \%$ \\
\hline Successfully Communicates & $68 \%$ & $72 \%$ & $56 \%$ & $49 \%$ & $74 \%$ & $79 \%$ & $60 \%$ & $75 \%$ \\
\hline Available & $68 \%$ & $89 \%$ & $69 \%$ & $54 \%$ & $72 \%$ & $84 \%$ & $76 \%$ & $79 \%$ \\
\hline Fair and Consistent & $72 \%$ & $83 \%$ & $61 \%$ & $63 \%$ & $79 \%$ & $81 \%$ & $74 \%$ & $80 \%$ \\
\hline Overall Effective Teacher & $72 \%$ & $78 \%$ & $56 \%$ & $44 \%$ & $77 \%$ & $\mathbf{8 2} \%$ & $64 \%$ & $79 \%$ \\
\hline
\end{tabular}

Table 5 shows a definite difference in perceived quality in nearly all areas between courses that have neither asynchronous online text-based or real-time webconferencing, and the baseline (see Table 3). In general student satisfaction is lower in Webcampus courses with no visible means of classroom course content discussions. However, courses that hold either weekly or periodic web conferences appear to support student satisfaction results similar to the baseline in most areas.

Table 5 shows a drop in perceived quality for courses with periodic online discussions and periodic real-time web conferences, versus courses with weekly online discussions and either periodic or weekly real-time web conferences. However, as a caution, due to the way the courses were categorized, this category has very limited course data and also reflects the only category where the students rather than the faculty led the discussions.

As shown, for courses with online discussions only (no web conferences), perceived quality was higher in nearly every area versus the baseline (see Table 3). However, the category in which faculty participated in the online discussions, versus faculty that did not participate in the online discussions, showed slightly higher overall perceived quality in most areas with the notable exception of 'The material was adequately covered in the allotted time.' This may be due to the additional time of lively discussions in the class leaving less time for other work.

A more detailed analysis is necessary to determine whether the real-time web conferences held in the online courses covered primarily course content or whether a majority of the time was spent on administrative issues, course logistics, or other non-course content topics. A cursory review indicates that the former assumption - that the web conferences were primarily for discussing course content - is most likely sound. 
Finally, there are many other components in the online classroom that were not considered in this analysis including instructor experience, class size, level of faculty interaction with students in other areas, etc. that could have had a significant impact on the findings. However, this analysis represents an initial investigation into the contribution of classroom discussions to the overall level of student satisfaction with the course experience.

\section{Best Practices and Lessons Learned}

The primary 'potential' lesson learned from this particular set of data relates to course quality versus instructor effectiveness. Students generally perceived instructor effectiveness as higher than course quality. In addition, the top four highest rated categories in student satisfaction with course quality were:

1. Asynchronous online discussion only (no web conferences) with faculty participation.

2. Asynchronous online discussion only (no web conferences) with little or no faculty participation.

3. Both periodic webconferences and weekly asynchronous online discussions with faculty participation.

4. Periodic webconferences (no asynchronous online discussions).

The top four highest rated categories in student satisfaction with instructor effectiveness were:

1. Asynchronous online discussion only (no web conferences) with faculty participation.

2. Both weekly webconferences and weekly asynchronous online discussions with faculty participation.

3. Periodic webconferences (no asynchronous online discussions).

4. Asynchronous online discussion only (no web conferences) with little or no faculty participation.

Based on the dataset, a best practice was evident in the use of asynchronous remote online discussions. In the 13 unique courses and 23 course deliveries that leveraged the use of course content related online discussions, more than half -7 versus 6 unique courses and 12 versus 11 delivered courses - did not include faculty participation. The category in which faculty participated in the online discussions, versus faculty that did not participate in the online discussions, showed only slightly higher overall perceived satisfaction in most areas of course and instructor quality with the notable exception of "The material was adequately covered in the allotted time." In general, in courses that leveraged asynchronous remote online discussions only, students were generally more satisfied with the course and instructor. 


\section{Future Research}

A natural follow-on would be to repeat the above approach with more data to see if the relationships are preserved and also to test for statistical significance in the findings. Next, a significant area of future research would be taking this analysis to the next step. That is, in the analysis for this paper, we only addressed the first level of Kirkpatrick's training evaluation framework: Reaction; which we related to student satisfaction. The next step would be to address Learning, followed by Behavior, and Results. (p. 19). ${ }^{6}$

On the other hand, the analysis may benefit by adding more criteria to the dataset. Experience has shown that class size, years of face-to-face teaching experience, years of online teaching experience, instructor and student level of comfort with online education and technology, and even educational philosophy or learning style of the instructor and/or students, are other examples of factors that may significantly impact student satisfaction and learning in the online environment. For example, Squires (2007) noted that the frequency and level of detail in faculty feedback appeared to have a significant impact on student satisfaction in the area of overall course and instructor quality. ${ }^{14}$ Squires (2006) found an increase in student satisfaction between deliveries of a fundamentals in systems engineering course where the content in first four courses was provided through a visual/text based format only; and in the following three courses the same content was enhanced by audio based lectures and speaker notes transcripts of that audio. However, student overall performance analyzed by looking at the feedback marks, did not appear to be affected. ${ }^{15}$ Further research combining the course content delivery and discussion methods may provide an avenue for taking the research to the next step.

Also, the course evaluation data provided for the Fall 2009 semester contained demographic data that included information on whether students worked full-time, parttime or not at all, and gender and age, if the student was willing to provide this information (most were). This data could be added to the baseline information for this analysis and might reveal insights into the effectiveness of a particular classroom discussion approach based on the student gender, age or work status. And last but not least, an analysis that categorizes the courses by level within the evolved INCOSE graduate systems engineering curriculum and classroom discussion may yield interesting findings on which class discussion pedagogy might be more effective based on the course content.

\section{Summary}

Online delivery of systems engineering education is not a one-size fits all. Different approaches can be successful, or not, depending on instructor style and other methods that the instructor uses to deliver content, feedback, or establish an online community. This paper looked at the effectiveness of various approaches to classroom discussions of the course content on student satisfaction with the learning experience. The analysis focused on the student's perception of course and instructor quality and various related attributes. The analysis of this particular dataset showed that the Fall 2009 online students were more satisfied with the course and instructor when the course included 
asynchronous online discussions only - whether the faculty participate in those discussions or not. Student satisfaction related to course quality and instructor effectiveness for those courses that leveraged real-time webconferences or the combination of real-time webconferences and asynchronous online discussions, were mixed. Although the results from this analysis apply only to the dataset analyzed, the findings can guide online course developers in making decisions on how they will address the need for classroom discussion on course content as part of the successful delivery of online education in systems engineering or any field; however, further research is needed to validate the findings.

\section{Bibliography}

1. Allen, I. E. and Seaman, J. (2008) Staying the Course: Online Education in the United States, 2008 Needham MA: Sloan Consortium

2. Armstrong, J., Henry, D., \& Pyster, A. (2009, September 8). Systems engineering, systems integration, and software engineering competencies required for successful acquisition of the next generation air transportation system. Hoboken, NJ: School of Systems and Enterprises, Stevens Institute of Technology.

3. Bender, T. Discussion Based Online Teaching to Enhance Student Learning: Theory, Practice and Assessment. Sterling, VA: Stylus, 2003.

4. Fredericksen, E., Pickett, A., Shea, P., Pelz, W., Swan, K. (2000). Student Satisfaction and Perceived Learning with Online Courses: Principles and Examples from the SUNY Learning Network. Journal of Asynchronous Learning Networks, Volume 4, Issue 2 - September 2000.

5. Garrison, D. R., Anderson, T., Archer, W. (2001). Critical thinking, cognitive presence, and computer conferencing in distance education. American Journal of Distance Education, 15(1), 7-23.

6. Hillman, D. C., Willis, D. J., \& Gunawardena, C. N. (1994). Learner-interface interaction in distance education: An extension of contemporary models and strategies for practitioners. The American Journal of Distance Education, 8(2), 30-42.

7. Kirkpatrick, D. (1998). Evaluating Training Programs: The Four Levels. 2nd ed. San Francisco, Berrett-Koehler Publishers, Inc.

8. Moore, M. (1989). Editorial: Three types of interaction, The American Journal of Distance Education, $3(2), 1-6$.

9. Parker, A. (1999). Interaction in Distance Education: The Critical Conversation. AACE Journal, 1 (12), pp. 13-17. Charlottesville, VA: AACE.

10. Pennotti, M., Smith, C., \& Verma, D. (2004). A systems engineering approach to the design of asynchronous online systems engineering courses. In Proceedings from the international systems engineering conference (ICSE) and the international council of systems engineering (INCOSE) 2004 region II conference, las vegas, nevada, september 15-18, 2004.

11. Reichheld, F. F. (2003). The one number you need to grow. Harv Bus Rev, 81(12), 46-54, 124.

12. Sener, J, Humbert, J. (2002) Student Satisfaction with Online Learning: An Expanding Universe. Elements of Quality Online Education: Practice and Direction, Volume 4 in the Sloan-C series.

13. Squires, A. \& Cloutier, R. (2010). Evolving the INCOSE reference curriculum for a graduate program in systems engineering. Systems Engineering, 13(4). [See Early Version available through Wiley Interscience.]

14. Squires, A., \& Pennotti, M. (2007). Measuring the value of course components applied in the online classroom. Proceedings of the 2007 american society for engineering education (ASEE) annual conference and exposition, honolulu, hawaii, june 24-27, 2007.

15. Squires, A., Pennotti, M., \& Verma, D. (2006). The effect of incorporating verbal stimuli in the online education environment: An online case study. Proceedings of the 2006 american society for engineering education (ASEE) annual conference and exposition, chicago, illinois, june 18-21, 2006.

16. Swan, K., Shea, P., Fredericksen, E., Pickett, A. \& Maher, G. (2000). Course Design Factors Influencing the Success of Online Learning. In Proceedings of 2000 (pp. 513-518). Chesapeake, VA: AACE. 